\title{
Health and well-being implications surrounding the use of wearable GPS devices in professional rugby league: A Foucauldian disciplinary analysis of the normalised use of a common surveillance aid.
}

\section{Luke Jones, Phil Marshall and Jim Denison \\ Introduction}

Over the last ten years the wearable GPS tracking device has become a commonplace coaching aid across most professional field sports (Aughey, 2011), including most rugby football codes (Twist \& Worsfold, 2014). Until recently it has been largely accepted that the use of surveillance technology to assist performance analysis in sport should be considered as a positive phenomenon that leads to improved performance outcomes and reduces the chance/likelihood of injury (Carling, Wright, Nelson, \& Bradley, 2014). It is now accepted as normal for coaches and athletes to use wearable GPS technology to record day-to-day outputs from training and competition. As a result of this norm, athletes are also expected to comply with the employment of these devices in training and matches. It is also now considered to be routine practice for coaches, in consultation with their strength and conditioning team, to use GPS data to design and implement training sessions (Aughey, 2011). Conventional wisdom dictates that these wearable GPS tracking devices assist the coaching staff of professional rugby league clubs by providing them with objective data about the movements of players' bodies. This data can then be used to maximise training levels and to prevent injury. However, up until this juncture, the health implications surrounding the everyday use of wearable GPS tracking technologies amongst elite athletes are, as a result of limited longitudinal research, poorly understood. In the current study we looked more closely at how GPS devices are actually being used and the impact that the presence of constant surveillance 
is having upon the physical, psychological, and emotional health of rugby football workers.

Existing research has warned that the physical, mental, and emotional health of athletes may be compromised as a result of the abuse or misuse of contemporary surveillance technologies (Groom, Cushion, \& Nelson, 2011; Author \& Toner, in press; Manley, Palmer, \& Roderick, 2012; Taylor, Potrac, Nelson, Author, \& Groom, 2015; Williams \& Manley, 2014). These papers adopt a post-structural stance and predominantly suggest that sport needs to be considered as a 'modern discipline' (Shogan, 1999) and that within sport, surveillance technologies operate as 'instruments of discipline' (Author \& Toner, in press) to ensure the application of the disciplinary techniques common therein. This arrangement renders working athletes as 'docile sportsworkers' who unquestioningly comply with the norms from within their workplace, including those which may be potentially damaging to their health. This body of research has also suggested that the implications of the constant monitoring and control of the movements of elite performers in sports settings requires further attention (Manley, et al., 2012) in order to procure a more balanced and comprehensive appreciation of the varied consequences of using surveillance technologies in sport.

In this particular investigation we utilised the disciplinary analysis of Michel Foucault (1991) to investigate how Head Coaches of professional rugby league teams use wearable GPS technology. We did so to reveal any associated problematic effects that the use of GPS may be having for working players' health and wellbeing. As Foucauldians, it was our intention to challenge the dominant 'truth' that promotes surveillance technologies as 'universally beneficial' (outlined in Author \& Toner, in press), and 
instead to advocate for a more balanced interpretation, one that cautions against the unknown effects of this now ubiquitous contemporary coaching tool. To collect our data we engaged in a number of semi-structured interviews with three performance analysts/strength and conditioning coaches at three different Super League clubs across the North of England.

\section{Literature Review}

Rugby league is a high intensity collision sport which places significant physical and physiological demands on participants. Players are expected to possess competence in a wide range of physical characteristics, including aerobic fitness, speed, agility, strength and power (Johnston, Gabbett, \& Jenkins, 2014). Match play requires participants to be able to cover considerable distances, approximately $6,000-7,800$ metres depending on playing position (Austin \& Kelly, 2014). Taken together the considerable demands of match play, along with the diverse demands of weekly training, place significant demands on the bodies of players. Injuries are common (Gabbett, 2004), with injury rates across playing levels as high as 148 per 1000 hours of match play time (King, Gissane, Clark, \& Marshall, 2014).

Perhaps it is unsurprising that rugby league as a sport and rugby league clubs in particular have taken an interest in the growing range and complexity of monitoring technologies that are now available. Among the most prevalent of these technologies in rugby league are GPS systems. Typically these systems include more than just a global positioning system and also incorporate accelerometers, magnetometers (Cummins \& Orr, 2015) alongside heart rate monitors. Over recent years the rapid development in the technology associated with these systems has given rise to a wide range of studies which have sought 
to provide a better understanding of the sport and its demands. For clubs these systems represent not just a way to maximise the outputs from their financial outlay on players, but also a way to protect their investment in these players by improving injury prevention and detection.

With access to surveillance technologies, the output of a club's 'machinery' (their playing staff) can be observed and closely recorded on a daily basis. In the elite rugby league setting, like with many sports, a common-sense-belief exists that suggests that "leaving athletes unsupervised to make mistakes... is not an option if athletes are to be managed effectively" (Author, Mills, \& Author, 2013). As noted at the outset, as a result of this controlling mentality, and because of its ability to monitor players so stringently, surveillance technology (including wearable GPS devices) has now become an accepted component of the coaching process and are widely utilised across field sports, including both professional rugby codes (Aughey, 2011; Twist \& Worsfold, 2014). It is telling that the main focus of existing research surrounding GPS focuses upon the functionality and benefits of certain platforms, rather than any discussion of the influence of this practice upon the coaching process as a complex social entity (Nelson \& Groom, 2012). As social science researchers, this, to us, seems short sighted, given that it has been identified on numerous occasions that the coaching environment needs to be considered as a complex and power laden social context (Cushion \& Jones, 2006; Jones, Armour \& Potrac, 2003). We believe that in order to understand the impact of wearable GPS tracking devices and their role in the coaching process, it is essential to go beyond discussing the quality, validity or applicability of data they generate. Instead, we suggest that it is necessary to consider the powerful consequences (both intended and unintended) of their regular use, 
not least with regard to the physiological, psychological, and emotional health implications for sports-workers (in this instance - professional rugby league players).

Manley et al (2012) have noted that, "little research exists surrounding the extent to which surveillance mechanisms are employed within sporting institutions, how they are structured and their impact upon the individual” (p. 305). However, some recent studies have adopted a post-structural position to warn against the dangers of an unthinking application of surveillance technologies in elite sport settings (Taylor et al., 2015; Williams \& Manley, 2014). These cautionary articles suggest that the imposition of disciplinary power upon working athletes within the coaching context is being ably assisted by surveillance technologies (including wearable GPS tracking devices). They also identify that the use of surveillance technologies accelerates and increases the effects of localised discipline that contributes to the fabrication of sporting 'docile bodies' (Markula \& Pringle, 2006), a process already associated with numerous dangerous/limiting short and long term outcomes for athletes (Barker-Ruchti \& Tinning, 2010; Author, 2007; Johns \& Johns, 2000: Author \& Author, 2016).

\section{Theoretical Framework}

Foucault (1978) was a post-structuralist philosopher who examined the sociohistoric relationships between power, knowledge, and the human body. He frequently warned against the dangers of blindly accepting 'dominant discourses' or 'ways of knowing' and the 'truths' that they produce. Foucault's work also warns that it is important for the individual researcher to be careful of 'Scientific Normativity'. This includes how the modernist narrative of a trajectory of progress (Cahoone, 2003) 
influences our relationship with technology (including its perceived role as a beneficial tool for the shaping of the healthy body in today's society).

According to Foucault (1991), in the transition to modern society the body became both the object and target of power. Central to the functioning of this power was an integrated system of control intended "to make useful individuals". To explain the precise details that characterized this transformation of the individual, Foucault (1991) outlined four specific techniques, or 'disciplines', and illustrated how they "made possible the meticulous control of the operations of the body" (p. 137). These four techniques were: the art of distributions that involved how bodies were managed and used in spaces; the control of activity that involved how bodies were shaped by time in these spaces; the organization of genesis that involved the way specific bodily practices were categorized and grouped; and the composition of forces that involved the way bodies were brought together to function as a machine. Importantly for Foucault, these techniques did not operate in a disjointed or fragmented manner; rather they worked together to exert their influence over the body through three specific instruments: hierarchical observation, normalizing judgment and the examination. Foucault explained that the collective power of these techniques and instruments assured the body's subjection—its 'docility'.

Underpinning Foucault's (1991) analysis of the making of docile bodies was his understanding of panopticism, a concept he based on Jeremy Bentham's architectural figure of the panopticon. According to Foucault, "the panoptic mechanism arranges spatial unities that make it possible to see constantly and to recognize immediately...assuring the efficient and automatic functioning of power" (p. 201). Thus, 
Foucault was able to show how in large social institutions where disciplinary regimes are prevalent, such as factories, the military, schools and hospitals, people can easily be transformed into cogs in a system where interaction, learning and personal growth are subservient to the large scale production of all: "an infinitesimal power over the active body...its movements, gestures, attitudes, rapidity" (p. 137).

At this point we would like to assert that we are not naive, and that we are not calling for a total abandonment of closely monitored and stringent training methods. For example, we recognise that certain technologies of discipline are necessary components of the provision of a safe environment for the working lives of rugby players (to list just two examples of many, learning correct tackling technique to avoid concussion takes time, careful instruction, and repetition, as does essential regular strength and conditioning work in the gym in order to prevent injury). However, many of sport's workplace practices have, due to discipline's celebrated status within sport, escaped appropriate levels of scrutiny (Heikkala, 1993). And, it is abundantly clear that Foucauldian thinking has a productive history when examining the previously unknown effects of discipline in certain sporting contexts (Markula \& Pringle, 2006). For example, several sports scholars have used Foucault (1991) to identify how sporting practices are sights of power that operate in localised settings to produce 'docile bodies' (BarkerRuchti \& Tinning, 2010; Author, 2007; Shogan, 1999). Foucault's (1991) disciplinary analysis has also been utilised to warn that taken-for-granted coaching knowledge(s), and the subsequent practices they inform/produce, can have potentially dangerous outcomes for coaches and athletes (Author \& Avner, 2011). Foucauldian scholars have also suggested that these problematic practices are clearly connected to the limitations 
associated with the negative aspects of elite sport (Johns \& Johns, 2000), and that therefore they are practices that must be re-imagined to avoid damage to individuals. For example, Hickey and Kelley (2008) and Author and Author (2016) have identified that unnecessarily disciplinary coaching practices that occur during a football career (of any code) have extremely significant effects for the individual player's physical, psychological, and emotional health in retirement.

Author and Toner (in press) have recently utilised Foucault's (1991) disciplinary analysis to critique the misuse of surveillance technologies in professional sport. These authors identified that an objective, outcome-based paradigm stemming from a dominant, modernist bio-scientific discourse surrounding the body has, so far, yielded overwhelmingly positive attitudes towards surveillance based performance analysis technologies. They also noted that this status quo has prevented a balanced appreciation of the consequences of the use of surveillance technology in coaching from emerging. In the present study we also drew upon Foucault's (1991) disciplinary analysis to critique the contemporary use/misuse of wearable GPS technology in elite rugby league. We believed that this was a sports setting where the use of surveillance technology could be imposing "unnecessary or excessive domination" (Author, Pringle, Cassidy, \& Hessian, 2015, p. 74) upon working athletes. Like these authors, we conducted this research with the intention of highlighting a specific aspect of elite sports coaching that might change in order to "foster more positive and less limiting sporting contexts" (p. 72). In short, we aimed to find a problem that has been normalised and critique it in an effort to make space for coaches to do a better job moving forward. We attempted to achieve this ambition here by suggesting where the normalised use of surveillance technologies may 
be being detrimental to the physical health and emotional wellbeing of professional rugby league players.

\section{Methodology}

The current research was conducted using a Foucauldian, post-structural stance that appreciates multiple truth claims and holds power as productive, ever-present, and relational (Markula \& Silk, 2011). Nelson, Potrac, and Groom (2014, p. 81) have noted that post-structural thinking is a useful tool in coaching research to "disrupt, challenge and problematise existing practices and thinking”. Because of these listed strengths, we adopted a Foucauldian, post-structural stance to examine the problematic effects of a current 'dominant truth' (Avner, Author, \& Author, 2014, p. 45) surrounding the application of one specific set of practices within the coaching of professional rugby league. We interrogated the entrenched assumption that the application of surveillance technologies to a coaching scenario leads to a direct improvement in an athlete's performance and the automatic maintenance of said athlete's health.

Participants were identified through a process of purposeful sampling (Sparkes \& Smith, 2014). As such they were selected as being potentially rich sources of information, working in the environment which formed the focus of this project - elite level rugby league. Institutional ethical approval was granted prior to recruitment. A total of three performance analysts/strength and conditioning coaches, working at First Utility Super League and Kingstone Press Championship clubs across the North of England, were recruited. Participants had between one and four year's experience working in these roles. 
Using our understanding of Foucault's (1991) analysis of discipline we devised a Foucauldian inspired interview guide (Avner et al., 2014) that we hoped might help to uncover how coaches make decisions surrounding the use of GPS data, and how these decisions might be contributing to unhealthy outcomes for working rugby league players. Each participant was interviewed twice, with interviews lasting between one and two hours. One-to-one semi-structured interviews were employed in this study as they allow for the detailed exploration of the beliefs, attitudes and opinions of an individual on a given subject (Purdy, 2014). Their strength lies in the fact that an interview guide can be constructed to guide questioning, while still allowing a considerable degree of flexibility during the interview process to explore new areas and new information which may emerge (Purdy, 2014). It is also important to acknowledge that the men we interviewed are qualified experts in the application and day to day use of wearable GPS technologies; however they are not Rugby League Head Coaches. Our investigation centred upon the views of these experts with regard to how they observed wearable GPS devices being employed on a daily basis in a rugby club environment, and how they observed Head Coaches and other support staff such as performance leads and physiotherapists, using the data generated from the GPS technologies.

Markula \& Silk (2011) noted that when undertaking data analysis, it is important to do so in correlation with the epistemological traditions of the paradigmatic approach that governs the research as a whole. From our poststructuralist perspective, the process of verification of the research process to ensure precise objectivity or repeatability is not necessary. Rather, research from this paradigm concentrates upon clearly understanding the meaning making of an individual situated within a specific socio-cultural context in 
order to shed light upon the workings of power in that specific space. This does not however negate the need for poststructuralist researchers to undertake a comprehensive analysis process. They must clearly stipulate how they analyse their empirical material through their theoretical lens. Our interview data was transcribed analysed using Foucault's (1991) disciplinary analysis. Each script was carefully observed and annotated and relevant quotes were deciphered and explained using Foucault's techniques and instruments of discipline and his panoptic stance.

\section{Results}

Our results indicated that in certain instances data from wearable GPS was often used (as intended) to protect the health and wellbeing of players. As Connor mentioned, You want your full squad available at all times. So if someone isn't well or the data shows they are suffering with stress of fatigue...if we train them there is a chance of injury. So we've got these systems in place to try and prevent injury. To protect them really. It's helping us but helping them. To protect them but to enable us to have as strong a squad as possible or more players available without injury.

However, despite this initial seemingly positive response, it quickly became apparent that the vast majority of anecdotes from John, Michael, and Connor, identified three less than optimistic themes. Firstly, that the data generated from wearable GPS is often totally ignored despite being specifically produced in order to protect an athlete's health and wellbeing. Secondly, that GPS generated data is utilised as a 'disciplinary tool' to normalise and coerce rugby league players to comply with the potentially unhealthy physical and psychological demands of a professional playing career. And, thirdly, that 
regardless of how the data gathered by GPS devices was utilised, the employment of wearable GPS devices was constant and rigorously implemented.

\section{Theme One: The dismissal of data generated from wearable GPS devices.}

As a result of our discussions with John, Michael, and Connor, it became quite clear that Head Coaches often simply ignored the GPS data produced by the wearable devices. Instead, the Head Coaches acknowledged the presence of GPS (as an innovative component of sports science) in order to present a progressive facade to the media. This stance was adopted to increase a coach's popularity and to garner support from wider stakeholders. For example, when asked about his Head Coach's attitudes towards the data from GPS, John noted that,

His attitude towards the data is that it is there to tick a box. Every other club is doing it - so we should be doing it. But we don't actually make it impact upon our practice...The coaches' attitude is to look at it from a superficial point of view and then to toss it away. Rather than looking at the data, or asking to have it explained, from my experience the coach has been very dismissive.

In another quote verified that the application of GPS was often used as a front by coaches to win over owners and fans. As John also mentioned,

A coach needs the backing of the owners and the fans. So, a coach can easily create an image where he is in charge of a team where science is being applied. For example if you produce a media article about how you are measuring x,y, and $\mathrm{z}$, it is easy for a coach to create the perception that they are being innovative when the reality might be radically different, and the truth is the use of technology is not really impacting practice at all. Even though the coach is painting the 
picture that he is doing everything he can to get the best out of the players - it is far from the truth.

Not only was GPS used to give the impression that contemporary coaching methods were being adopted, our participants were also privy to several incidents where the data from GPS was completely ignored as it contradicted an 'expert coach's' desired approach to practice. We heard from Connor that his Head Coach would "routinely decided to let sessions run longer in contradiction to the agreed training load". And, in one vivid example, clear risks to athlete health were identified and readily dismissed during a preseason period.

John: In terms of bad practice? We had one occasion where the spikes in training load; we went from a $150 \%$ increase to another $100 \%$ the week after.

Interviewer: A $250 \%$ increase over a three week period?

John: Yes that's right. If we hadn't had the technology we wouldn't have realised that it had gone up that much, but we did. So, we reported that it had gone up that much - that should have had alarm bells ringing quite clearly - 'we've gone up really high this week'- so, you'd think - next week we should stay at the same level or drop (laughs) - but they went up again! They weren't taking on board what we said and they didn't understand the magnitude of the increases in training load.

This sort of incident was not isolated within one club; another occasion was recalled by Michael, who, at a different Super League club, overheard a heated discussion between the Head Coach and the Head of Sports Science, 
I heard the Head Coach say 'Fucking Hell! We've have loads of injuries, the boys seem knackered'. We'd started the season really poorly; I think we'd lost the first three games. And the Head of Sports Science said 'Well look at pre-season, you've absolutely smashed them. You haven't followed what we said, you've followed what Billy (Assistant Coach) had said and now they're knackered'. And, in another context, Michael recalled how in the run up to the final of the same season, all advice that Sports Science staff provided from recorded data was disregarded, The week leading up to the final they literally didn't ask me a thing. I used to give them reports about how to keep them fresh, but they absolutely flogged them the week before the final and obviously we lost $\mathrm{xx}-0$ and it was a Super League record and it was like, what do you expect?

In the instance above the team lost heavily, however we suggest that the trend established by our interview responses indicates something much more pernicious - a normalised disregard for player health in the face of clear data. This is something we find extremely problematic, but given recorded attitudes towards pain and injury within the hypermasculine culture of all rugby football codes (Light \& Kirk, 2000; Liston, Reacher, Smith, \& Waddington, 2006; Pringle \& Markula, 2005), one we do not find surprising.

\section{Theme Two: Wearable GPS data as a 'disciplinary tool'.}

Techniques of discipline - docile bodies.

Several responses from our interviews highlighted how Head Coaches attempted to shape a player's behaviour and physiological outputs as a result of using threats that emanated from data recorded by GPS data. Michael identified that, 
I remember last year one player was way off on his high speed and total distance. I gave this data to the Head Coach direct. He saw it and got him into the office. This year he has got a lot of people in the office based on the data...Obviously they are not performing well via the data. So, I think it's to give them a kick up the arse really. If you want to be playing, you need to be impressing the staff that are there, and, if you haven't done enough and the data shows that, there is a good chance they won't pick you.

And, on another occasion when a player wasn't meeting certain expectations based upon GPS records he could not make the first team squad, Michael recalled that,

The Head Coach would look at high speed running and high speed running percentage. That's the one thing he looks at when using GPS. He'll highlight that. Because the higher that is the more you're trying to train at game intensity, which is going to benefit you when you come into a game...So I know for a fact that one player was left out of the squad for ages because he wasn't meeting the standards, but he gradually improved - you could see the percentage going up, so the head coach brought him in and said look - eventually you could end up in the squad.

It is clear from these two responses that the data generated by GPS devices are frequently applied as a tool for the imposition of disciplinary power upon working rugby league players. Foucault (1988, p. 18) identified how specific social practices “determine the conduct of individuals and submit them to certain ends of dominance".

In his disciplinary analysis, Foucault (1991) observed how an individual's actions were guided through the tactical manipulation of space, time, and movement. For example, Foucault's (p. 141) first technique of discipline, the 'art of distribution' 
concentrated upon how "discipline proceeds from the distribution of individuals in space". In the above quotes, as a result of finitely measuring a player's movement on the clearly demarked space or 'enclosure' of the rugby field, and by ritualising the dissemination of these data within the hierarchically relevant space of 'the office', GPS data contribute to a machinery of power that explores, breaks down, and then re-arranges the bodies of elite rugby league players.

Foucault also identified that to impose discipline upon a body, one could use time and the timetabling of activity to ensure that the "body is constantly applied to its exercise" (p. 151). Therefore, the imposition of disciplinary power onto bodies also occurs when coaches use measures of time to regulate how a rugby league player moves within his designated 'enclosure' (the training field or match day arena). Therefore, any attempt to use GPS data to increase a player's 'high speed and total distance' over a particular period through an organised, timetabled training schedule, highlights how Foucault's second technique of discipline, the 'control of activity' is mobilised by GPS data in this particular context.

Foucault's (1991) third technique for executing discipline upon an individual body was to gradually increase the nature and complexity of required exercise - for example a graduation from reserve team to the first team squad (the very incentive described by Michael in the above quotations). This intentional evolution of activity prescription is common in elite sports circles, and is more easily activated due to the level of knowledge surrounding an individual that technologies such as GPS allow. For Foucault this 'Organisation of genesis' disciplines by clarifying each athletes level or rank, and is a practice that leads to the prescription of graduated exercises that in turn, 
govern desired behaviours such as obedience and the acceptance of certain expectations. To be clear, the process of correction that uses GPS data is one of many that produces "subjected and practiced bodies, 'docile bodies"” (Foucault, 1991, p. 138), and ensures that the bodies of rugby league players are constantly subjected to forces which coerce them to perform a designated function - that of performing at a high level for their team. As Foucault (1991, p. 138) would have it, this "establishes in the body the constricting link between an increased aptitude and an increased domination". This is a process that occurs with greater efficiency within intentionally cordoned groupings - for example a squad of elite rugby players. This grouping is what Foucault (1991) called the 'composition of forces', and was the final technique of discipline he mentioned that worked to produce a new and productive machinery of individuals capable of better combining their forces in smaller cells.

Instruments of discipline - the means of correct training.

Our data highlighted that rugby league players are exposed to discipline as they are observed and monitored on a regular basis with the assistance of GPS tracking. Every movement they perform on the pitch both in training and matches can be recorded and used to punish players who fall short of prescribed expectations. When asked what surveillance devices allow practitioners to monitor, John explained,

The training load. For example, the distance covered - that can be gathered from GPS. Their speed and speed based variables as well. You have also got the recent introduction of metabolic power variables...total distance, sprinting distance, jogging distance, walking distance. You can also generate accelerometry data. Some clubs supplement by looking at blood and saliva and all sorts of things. 
The multiple movements a player makes are observed by a "hierarchically organised system of assistants" (Mills \& Author, 2016, p. 7) ranging from the performance analysts recording the data to the Head Coach. Via the manipulation and coding of this large amount of data, it becomes permissible to "know" and to potentially "alter" (Foucault, 1991, p. 172), players' output and behaviours. Not only is a huge amount of data generated from GPS, but the way in which it is generated is completely normalised and operates "innocently and efficiently" (Mills \& Author, p. 8). Once collected, the data can be utilised to generate knowledge surrounding a players' capabilities, strengths, or weaknesses. As John noted,

We know from the data the links between training load, injury and performance. So the ability to quantify that is a massive thing if you get it right. You can record and manage each individual player.

Therefore, what is clear is that this constant and normalised data collection allows for the development of an individual and personalised portfolio. Each individual becomes "a case to be known” (Dreyfus \& Rabinow, 1982, p. 159). This 'compilation of dossiers' (Shogan, 2007) allows for the collection of an incredibly intimate knowledge of every modern professional player, and can be utilised not only to taper appropriate training, but to enable the division of players within the club (development squad/reserve team), or for retain or release purposes. This process of subdivision enables an even closer and more efficient means of observation for future purposes of classification or comparison (for example selection). It is clear that the use of GPS surveillance secretes "a machinery of control that functions like a microscope of conduct; the fine, the analytical divisions" and forms around working players functioning as "an apparatus of observation, recording and 
training" (Foucault, 1991, p. 173). For example, via GPS tracking and heart rate monitors the movements and physiological outputs of rugby players are constantly recorded, leading to a process of what Foucault called "progressive objectification" taking place. Furthermore, through the infinite statistical analysis generated through GPS a detailed battery of knowledge about each player is established and compiled. This data can easily be accessed in order to correct any deviation from the required output or behaviour, as this quote from Michael indicates.

That is where the real utility comes in - to be able to quantify it and transfer that to design sessions - to be able to pull players in they are showing signs of overreaching or overtraining, to protect them. Or, to push them if the numbers show they are slacking off.

Let us consider for a moment the way in which the contemporary professional rugby player's movements are captured by wearable GPS. During training days and game days, because of GPS and the other instruments of surveillance in place, "all activities are recorded" and "all offences perceived and judged" (Foucault, 1991, p. 174). These activities and offences are captured and are set in stone. They can be repeatedly analysed by the Head Coach, the coaching staff, the expert pundit, the spectator and the journalist. Everything that a professional rugby league player does is now captured and recorded. GPS tracking possesses what Foucault (1991, p. 174) called a "special function". It also performs "an integral part of the production process" that is currently unquestioned by the majority (if not all) users of this technology. The relevant point is this, Foucault warned that disciplinary power is distributed subtly through hierarchical observation, and that wearable GPS tracking is an excellent example of how this observation occurs. 
GPS surveillance also imposes disciplinary power as it contributes to the maintenance of a 'normalising gaze' upon the working player. For example, another quote from Michael shows how the data from technology is reinforced by the gaze of two coaching staff members during an individualised running session,

He (coach) would measure out exactly the metres a player would cover in a game and replicate halves of competition from it. And I'd be there stood on the sideline with the live system set up, and he'd be shouting to me every twenty seconds 'How much? How much?', 'How fast was that sprint?' that kind of thing. What this example illustrates is that those responsible for the supervision of individuals (coaches) are complicit, but also are often unaware or dismissive of the significance of the role they play in maintaining this 'inescapable gaze'. As a result, the effects of disciplinary power continue and the 'means of correct training' a 'normalised' player preside. For Foucault (1991) the process of normalisation was central to the coercive production of 'docile bodies'.

The most common use of GPS data reported was as a barometer to govern training and to coerce players to abide by an accepted training norm. As Connor noted, The effectiveness of this (GPS) is governed by the knowledge and appreciation of the data by the decision makers. You can provide them with an intimate knowledge of each individual player, but ultimately they are not going to use it. There is a heavy reliance on ex-players within Rugby League clubs to be honest coaches who are ex-players are limited in their knowledge of how to use the data so they end up cherry picking it, and using it as a front for their own benefit or agenda. In one case the Head Coach was determined that players needed to work 
to a certain intensity in pre-season - so he abused the GPS data to enforce the workload he wanted to implement.

So instead of protecting individualised players' health by tapering their workload in line with individual capacity (as was the 'intention' of GPS tracking data) in this instance the data generated by GPS was manipulated by the coach to highlight whether a player (or group of players) was successful or unsuccessful in performing a normative action or behaviour. In this scenario "the power of normalisation is that it imposes homogeneity" (Foucault, 1991, p. 184) and reiterates what is expected of the working player, dissuading any deviation from the prescribed norm. Edwards and Usher (1994, p. 4) noted that the significance of imposing a norm is that it works by excluding.

The norm defines a standard or criteria of judgement thus identifying all those who do not meet the standard. In this way, a picture is provided of what a person is 'good at' and correspondingly where he/she is lacking or deficient.

Often these deficiencies, recorded by GPS devices and other methods of performance analysis (Groom \& Cushion, 2005) are used by coaches to expose a player in front of his peers. This public display of shaming is key to re-emphasising the message being delivered, and given the violent, hyper-masculine and competitive nature of the masculine sporting space (Cushion \& Jones, 2006), the affect is multiplied, leading to potentially damaging negative experiences (Manley et al., 2012; Taylor et al., 2015). For example, in this instance, due to compliance with the prescribed training load, several players experienced injury, as John explained,

By quantifying this increase in data I was able to pinpoint six or seven players who showed signs of danger and I advised the Head Coach that they needed to 
taper. However, he wanted everyone to reach the same standard established by the 'average data', so after two weeks my suggestions weren't really implemented in terms of adapting the session load, and as a result, three of those seven ended up with soft tissue injuries.

This incident exposes the dangers of a coach imposing normalising judgement through GPS data as an 'instrument of discipline'. As Foucauldians, we suggest that imposing “any kind of binary of 'permitted and forbidden' or 'standard and substandard', leads to individuals being judged according to a fixed set of truths. And, "if a coach is not careful, this judgement can begin to make all individuals feel that they need to be like one another by instilling a constant pressure to conform" (Author, et al., 2013, p. 395). Not only does normalising judgement imposed through the data generated by wearable GPS tracking devices focus upon the objectivity of players, it validates player output as a natural, neutral truth, untouched by power. This assumption has significant implications. For example, any mistake becomes firmly rooted in the player's abilities. Alternative decisions/opinions to those prescribed are considered deviant and even dangerous. And, most importantly, data attained through GPS technology can be 'hijacked' and manipulated to vindicate the dominant and established disciplinary practices and attitudes beloved by the in situ 'experts'. As it is, those practices and expectations are already considered to be objective truth and as such are set in stone. Any rugby player identified as failing to conform to the outlined expectations, "commits and 'offence', whenever he does not reach the level required" (Foucault, 1991, p. 179) while the justification for his punishment or banishment also remains unquestioned. 
When working rugby players' activities are monitored via wearable GPS, it is primarily for the purpose of examination - Foucault's (1991) third instrument of discipline. Foucault (1991, p. 184) noted that, "the examination combines the techniques of observing hierarchy and those of normalising judgement”. By combining these two powerful mechanisms, the examination makes it possible to "qualify, to classify and to punish" the individual under examination. A key element of the examination process is to establish "a visibility through which one differentiates... and judges". In $21^{\text {st }}$ century working rugby contexts, players are routinely examined in various ways, but more often than not, GPS is central to the exam, and is a "highly ritualised", and incredibly powerful act. As John explained,

John: On an annual basis we'll do testing beginning of pre-season. We do maximal aerobic speed with the WATT bike and Rower and then we'll re-test at the end of pre-season.

Interviewer: What other testing is done?

John: Heart Rate Variability - and you match that with the GPS to see 'well what did he do?' So you collect the GPS data over a number of weeks and compare it. That data then gives you a status of red, amber and green. Green is ok, amber is reduce load and red is 'off feet'.

The examination of working players exposed to surveillance technologies and fitness testing procedures is an important arrangement to analyse because, through "the deployment of force and the establishment of truth" it validates a knowledge of each individual, classifying this knowledge as certain 'truth'. This 'truth' can and often does 
remain fixed, leaving a player categorised forever in his working environment. As Connor noted, the data garnered by GPS becomes stored on a database.

It's stored on an Excel sheet with, like 8000 lines. Everything gets logged in that database, every session, whether its wrestle, field, a GPS session, off feet conditioning or weights. Everything gets logged in there. On the homepage every player's got a link and every player's got their own page.

This storage of data can for some represent a significant hurdle given the intensely hierarchized nature of professional rugby. For example, once a player is categorised by an examination, he has his output so closely monitored and recorded it is extremely difficult to assuage the truth that emerges from this objectification - to change a coaches mind about what he might be able to do or not to do. This circumstance can have a serious impact upon a player's career and professional mobility.

Our interviews also revealed that in the rugby setting, players are constantly monitored, during every game and training session. This "regular observation" places the player "in a situation of almost perpetual examination" (Foucault, 1991, p. 186). This constant re-examination, now part of the fabric of rugby, has led to working players becoming "a domain of objects perpetually offered for examination" (p. 186), and to an extent has helped to legitimise the normalisation of maximising player output based on objective data (often at the expense of a player's physical and emotional wellbeing). Furthermore, for Foucault (1991, p. 231), the prison was the perfect example of an institution that disciplined individuals. He described how power was imposed in great detail. 
Fixing them (bodies) in space, classifying them, extracting from them the maximum in time and forces, training their bodies, coding their continuous behaviour, maintain them in perfect visibility, forming around them an apparatus of observation, registration and recording, constituting on them a body of knowledge that is accumulated and centralised.

What could be more in line with this description than how wearable GPS tracking devices are being used across the clubs we considered? We have evidenced how GPS data classifies players, how it is coded by analysts to establish dossiers on each player, how it makes players constantly visible to be observed by a distinct hierarchy who record each player's every move. Our interviews have revealed that data generated from wearable GPS analysis is clearly and purposefully utilised in a disciplinary fashion - often as an 'instrument of discipline' specifically deployed to ensure the application of disciplinary techniques and hence the imposition of disciplinary power upon the docile bodies of working rugby players. Therefore, the main issue that we have identified in this study is that the docility incurred by what Foucault (1991) collectively termed the "techniques and instruments of discipline' are being increasingly mobilised by GPS data. As a result, players are continuing to perform their expected 'function' regardless of any limiting outcomes this may be having for their immediate or long-term health.

\section{Theme Three: Constant surveillance.}

\section{Panopticism.}

This conversation explains how the presence of GPS is omnipresent in the lives of working rugby league players.

Interviewer: So who enforces the wearing of the GPS units? 
Connor: 'It's from all the staff, so if they (the players) ever refuse to wear it or they forget to wear it, they get fined'.

Interviewer: What form do the fines take?

Connor: 'Pre-season it was physically, like punishment. Like, I don't know, ten 1000s on a Watt Bike and when it come into in-season it's monetary'. 'Last season, one thing they did with it, if one person forgets to wear the GPS, every player gets fined. So you try and bring the group together, so all the lads are reminding each other'.

Connor's recollection of punishment highlights how, despite the reported apathy on the part of the Head Coaches, wearable GPS devices were still religiously employed during all training matches and games. And, as these responses indicate, failure to comply with the everyday use of this chosen technology resulted in a punishments ranging from physical punishments and individual fines to collective punishments for the team as a whole.

Even though the Head Coaches often chose to ignore the data generated from GPS, we suggest that the very presence of the vests acts as constant mechanism of surveillance, and is, from a Foucauldian perspective, problematic. According to Foucault (1991) the workings of power are maximised within an arrangement where individuals are of the belief that they are constantly under surveillance - in what he called a 'panoptic' arrangement. In this arrangement both the docility and utility of individuals is increased. For Foucault (p. 197) this type of arrangement was an, enclosed, segmented space, observed at every point, in which individuals are inserted, in a fixed place, in which the slightest movements are supervised, in 
which all events are recorded...in which each individual is constantly located, examined and distributed.

Within a panoptic space of this nature, the imposition of disciplinary power is exquisitely facilitated by the perceived constancy of supervision (regardless of whether the supervision is 'real' or not). In such a space "the omnipresent gaze of authority subsequently disciplines the subjects to survey their own behaviours in a manner that renders them docile: they become their own supervisors" (Markula \& Pringle, 2006, p. 43). This self-supervision is a factor in sustaining the 'autonomous' utility of working players and also has the outcome of players learning to 'blame themselves' (Duncan, 1994) for failing to adhere to expected norms. This is a formula that when repeated on a daily basis can lead to a player wrestling with the powerful emotions of guilt and shame. And, as many mental health professionals have identified, an irrational and repeated internalisation of blame for 'mistakes' or 'failures' is often a central trigger for depression, neurosis, and character disorders (Peterson, Schwartz, \& Seligman, 1981; Tilghman-Osborne, Cole, Felton, \& Ciesla, 2008) - classic symptoms of undesirable mental health.

What we have observed through our results is that wearable GPS is an extremely significant component of the maintenance of constant supervision within the working rugby league setting. Regardless of how the data it generates is used by Head Coaches, the intensity and constancy with which this technology is routinely employed no doubt contributes to the panoptic and hence extremely disciplinary context of the rugby league workplace. 


\section{Discussion}

We do not intend to persuade coaches/strength conditioning practitioners to give up observing their players, lock, stock and barrel (for example it is clear that these actions are essential for the identification of concussion symptoms and to taper training to prevent injury). Rather, we believe that we have identified a real need for coaches to regulate or re-think their day-to-day use of surveillance based performance analysis technologies such as wearable GPS. We suggest that "effective coaches need to understand that increasing control may make peak performance less, not more, likely because it is more apt to lead to athlete docility" (Author et al., 2013, p. 395). We also suggest that, according to Foucauldian thinking, normalised practices (like the use of wearable GPS devices) can and should be rethought or even changed for the better (Author et al., 2015). As the Foucauldian scholar May (2006, p. 16) noted, the "historically given complex of practices through which we know...is contingent and therefore changeable" (italics added). We are of the belief that it is those in positions of power within the realm of elite sport who have a responsibility to exercise their ability to change troublesome practices for the better.

A closer examination of a particular dominant practice from the 'modern discipline' of professional rugby league has highlighted that not only is using surveillance technologies in a thoughtless manner potentially dangerous, but that coaches are at worst apathetic, and at best, worryingly ignorant surrounding the intricacies of why they might be dangerous. As Foucault noted in discussion with Dreyfus and Rabinow (1982, p. 187) "people know what they do; they frequently know why they do what they do; but what they don't know is what what they do does". Here, because we do not believe that 
coaches are fully aware of the implications of ubiquitous surveillance, like Author and Toner (in press) we continue to caution against the unregulated use of these types of technology. This constant surveillance, when mismanaged or adopted as a coercive disciplinary tool, magnifies the uncertainty and fear of failure that has been identified as central to the predominant challenges that arise during a working football career (Roderick, 2006). Markula and Pringle (2006, p. 47) noted that the level of surveillance we identified in rugby league might actually be having the opposite to its intended effect, Foucault did not suggest that the spread of disciplinary technologies actually resulted in the creation of a well-disciplined orderly society. Likewise, we suggest that one should not assume that the employment of disciplinary technologies in sport would necessarily produce well-disciplined athletes. In contrast a major argument developed by Foucault was that disciplinary institutions do not always produce their intended 'outcome'...Likewise, we suggest that the sporting disciplines that not only produce winners and 'moral characters' but also losers and the debauched, but more often subjects that are respectfully fragmented (italics added).

Could it be that through the constant monitoring of players, coaches are preventing what they are actually attempting to enact? It is not too far to suggest that the bodily crises (Toner et al., 2015) and health issues (physical, emotional, and psychological) that repeatedly emerge from elite football codes (Turner et al, 2000; Hickey \& Kelley, 2008; Author \& Author, 2016) are examples of the fragmented subjects that Markula and Pringle (2006) have warned us about? 
We assert that coaches need to reconsider what they are doing, and that applying and making decisions based upon the fixed knowledge gained from wearable GPS devices should not be celebrated as 'progressive' or 'innovative'. Rather, in certain cases, perhaps this ubiquitous surveillance acts as a retardant to the improvement or the development of a player. This is the great falsity of surveillance and control in sport that a coaching staff who fastidiously observe and repeatedly pass judgement from a position of power and expertise, do not cultivate 'innovative change', rather, they examine in order to discipline, simply because they know no other logic from which to draw upon (Author et al., 2015). By relying on their logic of discipline, they maintain a 'truth game' that can marginalise and segregate those players who refuse to conform or those who simply play or move in a way that does not comply with established norms. The knowledge surrounding players that this kind of coach creates, instead of being an ‘informed truth', ends up being only a manifestation of a coach's own expert knowledge, reified and cemented in place by the surveillance that he genuinely believes to be providing a neutral, revelatory assessment of a player's inherent capabilities.

\section{Conclusion}

The long-term consequences for the health and welfare of working rugby players of strict daily surveillance are yet to be fully understood. But, what is already clear is that in highly disciplinary sports settings - where deviations from expected norms are taboo maladaptive behaviours, 'bodily crisis' (Toner, Author, \& Moran, 2016), and mental health issues are prevalent (Johns \& Johns, 2000). Using Foucault's (1991) disciplinary analysis, our study has established that due to their regular misappropriation and constant presence, surveillance technologies like wearable GPS contribute to the unceasing 
imposition of disciplinary power upon working rugby league players. More specifically, as a result of the intimate levels of data generated by wearable GPS technology, the techniques and instruments of discipline that Foucault (1991) identified are more acutely mobilised within the elite rugby league setting. As a result of GPS data, the spaces within which athletes train can be more accurately refined (art of distributions), timetabling can be more individually tailored (control of activity), activities can be more logically graduated for efficiency (organisation of genesis), and group numbers optimised in order to increase training outcomes (composition of forces). These techniques, coupled with the in situ hierarchical instruments of surveillance (hierarchical observation, normalising judgement, and the examination) that as a result of GPS and other monitoring techniques, persist on a daily, even hourly basis, explain how wearable GPS technology is contributing to the production of a highly disciplined 'panoptic' elite Rugby League environment.

Due to the acute imposition of discipline that occurs in this daily environment, Rugby League players become 'docile bodies' that normalise and accept the unhealthy practices associated with the historical and modern traditions of this particular sporting context. Therefore, as a result of analysing GPS technology using Foucault's disciplinary analysis we can now contend that the extent and manner in which GPS analysis is utilized by rugby league coaching staff members needs to be recognised as a dangerous potential contributor to detrimental physical and emotional health amongst working rugby league players. We assert that these findings allow for a more measured and informed appreciation of the impact that GPS technology can have. And, that perhaps in time a more balanced viewpoint might replace the overwhelmingly positive and uncritical 
attitudes towards GPS and other surveillance technologies that currently prevail in elite Rugby League settings. Finally, we suggest that by drawing attention to the danger that the misuse of surveillance technologies can have for player health, it is hoped that this article might highlight the necessity of increasing the level of education for elite sports practitioners with regard to the application of wearable GPS devices and other surveillance technologies (see Harvey, Cope \& Author, in press; Author \& Toner, in press).

\section{References}

Aughey R. (2011). Applications of GPS technologies to field sports. International Journal of Sports Physiology and Performance. 6, 295-310.

Avner, Z, Author \& Author. (2014). Poststructuralism. In: Nelson L, Groom R and Potrac P (eds) Research Methods in Sports Coaching. London: Routledge. Austin, D.J., \& Kelly, S.J. (2014). Professional rugby league positional match-play analysis through the use of global positioning system. Journal of Strength and Conditioning Research, 28 (1), 187-193.

Barker-Ruchti N and Tinning R (2010) Foucault in leotards: Corporeal discipline in women's artistic gymnastics. Sociology of Sport Journal 27: 229-250.

Cahoone, L. (2003). From modernism to postmodernism. Oxford: Blackwell Publishing. Carling, C., Wright, C., Nelson, L. J., \& Bradley, P. S. (2014). Comment on 'Performance analysis in football: A critical review and implications for future research'. Journal of Sports Sciences, 32(1), 2-7. 
Cummins, C., \& Orr, R. (2015). Analysis of physical collisions in elite National Rugby League match play. International Journal of Sports Physiology and Performance, $10(6), 732-739$.

Cushion, C., \& Jones, R. (2006). Power, discourse, and symbolic violence in professional youth soccer: The case of Albion football club. Sociology of Sport Journal, 23,142-161.

Author (2007). Social theory for coaches: A Foucauldian reading of one athlete's poor performance. International Journal of Sports Science and Coaching, 2, 369-383.

Author,. \& Avner, Z. (2011). Positive coaching: Ethical practices for athlete development. Quest, 63, 209-227.

Author, Mills, J., \& Author. (2013). Effective coaching as a modernist formation. In P. Potrac., W. Gilbert., \& J. Denison. (Eds.). Routledge handbook of sports coaching. (pp. 388-399). London: Routledge.

Author, Pringle, R., Cassidy, T., \& Hessian, P. (2015). Informing coaches practices: Towards an application of Foucault's ethics. International Sport Coaching Journal, 2, 72-76.

Author, Mills, J., \& Konoval, T. (2015). Sports' disciplinary legacy and the challenge of 'coaching differently'. Sport, Education and Society, http://dx.doi.org/10.1080/13573322.2015.1061986.

Dreyfus, H., \& Rabinow, P. (1982). Michel Foucault: Beyond structuralism and hermeneutics. Chicago: The University of Chicago Press. 
Edwards, R., \& Usher, R. (1994). Disciplining the subject: The power of competence. Studies in the Education of Adults 26, 1-14.

Foucault, M. (1978). The history of sexuality. London: Pantheon Books.

Foucault, M. (1988). Madness and civilization: A history of insanity in the age of reason. London: Pantheon Books.

Foucault, M. (1991). Discipline and punish: The birth of a prison. London: Penguin Books.

Gabbett, T.J., King, T., \& Jenkins, D. (2008). Applied physiology of rugby league. Sports Medicine, 38, 119-138.

Gabbett, T.J. (2004). Incidence of injury in junior and senior rugby league players. Sports Medicine, 34 (12), 849-859.

Groom, R., \& Cushion, C. (2005). Using a video based coaching with players: A case study. International Journal of Performance Analysis in Sport, 3, 40-47.

Groom, R., Cushion, C., \& Nelson, L. (2011). The delivery of video-based performance analysis by England youth soccer coaches: towards a grounded theory. Journal of Applied Sport Psychology, 23(1), 16-32.

Harvey, S., Cope, E., \& Author. (In press). Coaching Behavior and Performance Analysis. In K. Dieffenbach., \& M. Thompson. (Eds.) Coach Education Essentials. Champaign, IL: Human Kinetics.

Heikkala, J. (1993). Discipline and excel: Techniques of the self and body and the logic of comepeting. Sociology of Sport Journal, 10, 397-412.

Hickey, C., \& Kelly, P. (2008) Preparing not to be a footballer: higher education and professional sport. Sport, Education, and Society, 13, 477-494. 
Johnston, R.D., Gabbett, T.J., \& Jenkins, D.G. (2014). Applied sport science of rugby league. Sports Medicine, 44, 1087-1100.

Johns, D., \& Johns, J. (2000). Surveillance, subjectivism and technologies of power: An analysis of the discursive practice of high performance sport. International Review for the Sociology of Sport, 35, 219-234.

Jones, R., Armour, K., \& Potrac, P. (2003). Constructing expert knowledge: A case study of a top-level professional soccer coach. Sport, Education and Society, 8, 213229.

Author \& Author (2016). Challenge and relief: A Foucauldian disciplinary analysis of retirement from professional association football in the United Kingdom. International Review for the Sociology of Sport. DOI: $10.1177 / 1012690215625348$.

Author \& Toner, J. (in press). Surveillance technologies as 'Instruments of discipline' in the elite sports coaching context: A cautionary post-structural commentary. Sensoria. DOI?

King, D., Gissane, C., Clark, T. \& Marshall, S. (2014). The incidence of match and training injuries in rugby league: A pooled data analysis of published studies. International Journal of Sports Science \& Coaching, 9 (2), 417-432.

Light, R., \& Kirk, D. (2000). High school rugby, the body and the reproduction of hegemonic masculinity. Sport, Education and Society, 5, 163-176.

Liston, K,. Reacher, D., Smith,. A., \& Waddington, I. (2006). Managing pain and injury in non-elite rugby union and rugby league: A case study of players at a British university. Sport in Society, 9, 388-402. 
Manley, A., Palmer, C., \& Roderick, M. (2012). Disciplinary power, the oligopticon and rhizomatic surveillance in elite sports academies. Surveillance and Society, 10, 303-319.

Markula, P., \& Pringle, R. (2006) Foucault, Sport, and Exercise: Power, Knowledge, and Transforming the Self. London: Routledge.

Markula, P., \& Silk, M. (2011). Qualitative Research for Physical Culture. New York: Palgrave MacMillan.

May, T. (2006). The philosophy of Foucault. Toronto: McGill-Queens Press.

Mills, J., \& Author. (in press). How power moves: A Foucauldian analysis of (In) effective coaching. International Review for the Sociology of Sport.

Nelson, L., \& Groom, R. (2012). The analysis of athletic performance: some practical and philosophical considerations. Sport, Education and Society, 17, 687-701.

Nelson, L., Potrac, P., \& Groom, R. (2014). The place of theory. In: Nelson, L., Groom, R., and Potrac. P (eds.). Research Methods in Sports Coaching. London: Routledge.

Peterson, C., Schwartz, S,. \& Seligman, M. (1981). Self-blame and depressive symptoms. Journal of Personality and Social Psychology, 41, 253-259.

Pringle, R., \& Markula, P. (2005). No pain is sane after all: A Foucauldian analysis of masculinities and men's experiences in rugby. Sociology of Sport Journal, 22, 472-497.

Roderick, M. (2006). The Work of Professional Football: A Labour of Love? London: Routledge. 
Shogan, D. (1999). The Making of High Performance Athletes: Discipline, Diversity, and Ethics. Canada: University of Toronto Press.

Shogan, D. (2007). Sport ethics in context. Canada: Canadian Scholars Press.

Taylor, W., Potrac, P., Nelson, L., Author., \& Groom, R. (2015). An elite hockey player's experiences of video based coaching: A poststructuralist reading. International Review for the Sociology of Sport. DOI:10.1177/1012690215576102.

Tilghman-Osbourne, C., Cole, D., Felton, J., \& Ciesla, J. (2008). Relation of guilt, shame, behavioural and characterological self blame to depressive symptoms in adolescents over time. Journal of Social and Clinical Psychology, 27, 809-842.

Toner, J., \& Author, \& Moran, A. (2015). Bodily crises in skilled performance: Considering the need for artistic habits. Performance Enhancement and Health. http://dx.doi.org/10.1016/j.peh.2015.10.001.

Turner, A,. Barlow, J., \& Heathcote-Elliot, C. (2000). Long-term health impact of playing professional football in the UK. British Journal of Sports Medicine, 34, $332-336$.

Williams, S., \& Manley, A. (2014). Elite coaching and the technocratic engineer: thanking the boys at Microsoft! Sport, Education and Society. Epub ahead of print 18 September. DOI:10.1080/13573322.2014.958816.

Twist, C,. \& Worsfold, P. (2014). The Science of Rugby. London:Routledge. 